\title{
Editorials
}

\section{Ten years of the Global Alliance for Vaccines and Immunisation}

BMJ 2010; 340 doi: http://dx.doi.org/10.1136/bmj.c2004 (Published 20 April 2010) Cite this as: BMJ 2010;340:c2004

\author{
Kelley Lee, reader in global health, Andrew Harmer, research fellow \\ ${ }^{1}$ London School of Hygiene and Tropical Medicine, London WC1E 7HT
}

kelley.lee@lshtm.ac.uk

Successes of immunisation are tempered by slow progress in strengthening health systems

The Global Alliance for Vaccines and Immunisation (GAVI), now known as the GAVI Alliance, was created in 2000 to increase the availability and use of immunisation in poor countries. GAVl's launch, which was made possible by a start-up grant of $\$ 750 \mathrm{~m}$ ( $£ 486 \mathrm{~m}$; $€ 550 \mathrm{~m}$ ) from the Gates Foundation, was part of broader efforts by world leaders to strengthen public health action across the globe in the late 1990s. Nine million children die in the developing world annually, two million from diseases for which vaccines are available. Over the past decade, GAVI has immunised 256 million children and, in doing so, has averted five million deaths.1

For many, the measurable achievements of GAVI make it the flagship among a flood of global public-private partnerships in health. The alliance has achieved this by playing a "market shaping role"-for example, by consolidating populations into larger markets and exerting downward pressure on prices (as it did for hepatitis $B$ and diphtheria-pertussis-tetanus vaccines) through its purchasing power. It has also politicised vaccines, in the best possible sense, and made world leaders recognise the importance of immunisation. The results are impressive, especially to donors seeking good news stories to leverage support for their funding decisions-the number of countries where polio is endemic has been reduced from 125 to four; 233 million additional children have been immunised against hepatitis $\mathrm{B}$; and the prospects of childhood vaccines for malaria and meningitis, and other new products are exciting. The recent announcement of an additional $\$ 10 \mathrm{bn}$ of funding to GAVI from the Gates Foundation is seen as a major vote of confidence for its work.2

Yet the alliance has not been immune to criticism. Although it is generally seen as an effective manager of an ambitious grant making enterprise, changes to its governance have been necessary to improve the quality and appropriateness of its funded activities. Of particular concern have been a lack of clarity about the relative roles of various partner institutions, the need for better technical support for countries applying for GAVI grants, and too little meaningful participation in priority setting by recipient governments. This last problem has led to familiar accusations of donor driven agendas and even the foisting of vaccines on recipient countries. 3 GAVI's governance structure was streamlined in 2008 when the alliance's two distinct decision making bodies-the GAVI Alliance board and the funding board-merged, with the aim of combining "the best of multilateral and public sector values and experiences with the added value of private sector dynamics and challenge."4

What is less clear is how this will ensure that the needs of recipient countries are taken into account. This raises difficult questions about GAVl's raison d'être, which—given a single minded focus on child immunisation—reignites longstanding tensions between vertical and horizontal approaches to health development.5 GAVI claims that immunisation is "one of the most efficient, successful and cost-effective health investments in history." 6 Others disagree, warning that insufficient attention to strengthening health systems skews priorities, diverts resources from 
other health needs, and creates unsustainable activities.7

GAVI sought to reconcile the disease and systems approaches by launching the Health Systems Strengthening (HSS) "investment window" in 2006. The goal of strengthening the capacity of health systems to deliver high quality immunisation services, and the principles behind achieving this (that they should be country driven, aligned with national planning and budget cycles, innovative, catalytic, and above all tackle unmet needs in existing support) have been widely supported. However, independent evaluations suggest much work remains to be done to realise this ambition. Lack of resources has not been the problem: HSS has been financed by the GAVI Fund and International Finance Facility for Immunisation (IFFIm), and there are reports of a planned HSS "financing platform" by the World Bank, Global Fund, and GAVI.8 The enduring challenge has been the lack of an agreed strategynotably, what exactly a health system is and what strengthening actions work best.9 Evidence suggests that GAVI grants have largely been used for downstream short term fixes, rather than the upstream long term structural reforms really needed to strengthen health systems.1011 12 More operational research is urgently needed to understand how GAVI might best support HSS for child immunisation that could, in turn, create a kind of "herd effect" in generating wider benefits for a broader range of health development needs.

The world is a better place for millions of children because of the increased rates of immunisation that GAVI has achieved over the past 10 years. The challenge is to ensure that these children go on to live their lives meaningfully and with dignity. This will require equitable access to the full range of basic needs, and to this end, the world still has a long way to go.

\section{Notes}

Cite this as: $B M J$ 2010;340:c2004

\section{Footnotes}

- Competing interests: All authors have completed the Unified Competing Interest form at www.icmje.org/coi_disclosure.pdf (available on request from the corresponding author) and declare: (1) No financial support for the submitted work from anyone other than their employer; (2) No financial relationships with commercial entities that might have an interest in the submitted work; (3) No spouses, partners, or children with relationships with commercial entities that might have an interest in the submitted work; (4) No non-financial interests that may be relevant to the submitted work.

- Provenance and peer review: Commissioned; not externally peer reviewed.

\section{References}

1. GAVI Alliance. Facts and figures. www.gavialliance.org/media centre/facts/index.php.

2. Gulland A. Gates Foundation gives $\$ 10$ billion for research and delivery of vaccines. BMJ2010;340:c650.

3. Chee G, Molldrem V, His N, Chankova S. Evaluation of GAVI phase 1 performance. Abt Associates, 2008www.gavialliance.org/resources/GAVI_Phase1_Report_FINAL to SC Oct21.pdf.

4. Adlide G, Rowe A, Lob-Levyt J. Public-private partnership to promote health: the GAVI Alliance experience. In: Clapham A, Robinson M, eds. Realizing the rights to health. Vol III. Swiss Human Rights Books, 2009:539-47.

5. Mills A. Mass campaigns versus general health services: what have we learnt in 40 years about vertical versus horizontal approaches? Bull World Health Organ2005;83:315-6.

6. GAVI Alliance. The GAVI Alliance. 2009. www.gavialliance.org/resources/3EN GAVI Alliance10 09 web.pdf.

7. Muraskin W. The Global Alliance for Vaccines and Immunization: is it a new model for effective public-private cooperation in international public health? Am J Public Health2004;94:1922-5.

8. Global Fund to Fight HIVIAIDS, Tuberculosis and Malaria. Report of the executive director. 20th board meeting, Addis Ababa, Ethiopia, 9-11 November 2009. www.theglobalfund.org/documents/board/20/GF-BM20-

03 Report of the Executive_Director.pdf. 
9. Naimoli JF. Global health partnerships in practice: taking stock of the GAVI Alliance's new investment in health system strengthening. Int J Health Plan Manage 2009;24:3-25.

10. HLSP. GAVI health systems strengthening support evaluation 2009. Vol II. Full evaluation report. 2009. www.gavialliance.org/resources/Volume 1 Key FindingsRecs GAVI HSS Evaluation FINAL Report 8th October 2009.pdf.

11. Goeman L, Galichet B, Porignon DG, Hill PS, Hammami N, Essengue Elouma MS, et al. The response to flexibility: country intervention choices in the first four rounds of the GAVI Health Systems Strengthening applications. Health Policy Plan2010, published online 1 February.

12. Galichet B, Goeman L, Hill PS, Essengue MS, Hammami N, Porignon D, et al. Linking programmes and systems: lessons from the GAVI health systems strengthening window. Trop Med Int Health2010;15:208-15. 